\author{
Carmen Pagliari \\ University of Chieti-Pescara, Department of Philosophical, \\ Pedagogical and Economic-Quantitative Sciences, Italy \\ e-mail: carmen.pagliari@unich.it
}

Iacopo Odoardi (corresponding author)

University of Chieti-Pescara, Department of Philosophical, Pedagogical and Economic-Quantitative Sciences, Italy

e-mail: iacopo.odoardi@unich.it

\title{
Improving the Relationship between Welfare Economics and Ethics
}

\begin{abstract}
In this essay, the essential aspects of Welfare Economics are summarized in order to analyse the possible links with Ethics, and consequently to provide useful suggestions for Economic Policy. The Introduction contains the principles of neoclassical Welfare Economics, without considering the circumstances in which the so-called failures of competitive markets occur. The second part of this paper contains a description of two possible solutions to the problem concerning the integration of Welfare Economics and Ethics. The first solution is the determination of the optimal combination of general competitive equilibrium principles and social ethics ones, without removing the theoretical structure of Welfare Economics. This first proposal, while retaining some economic liberalism principles, assigns a central role to the government, which is delegated to superimpose on the Pareto criterion a distributive justice rule. Another solution, which is suggested by Sen, is essentially directed to modify Welfare Economics by ethical criteria aimed at improving every individual deprivation, and it is based on the distinction between the two concepts of 'utility' and 'agency'. We also proposed exploiting the original considerations written by Smith about social aspects as a useful integration and support to Sen's approach.
\end{abstract}

Keywords: Welfare Economics, Methodological Individualism, Allocative Efficiency, Ethics JEL Classification: D60, D61, D63, I31 


\section{Introduction}

The analysis contained in this paper is mainly based on the individuation of ethical criteria for the achievement of collective welfare, focusing on the positive contribution that a closer relationship between economic policy ${ }^{1}$ and ethics could give to the first of these disciplines.

In particular, the integration of welfare economics and ethics seems to be a necessity in the contemporary evolution of global economics, characterized by a growing polarization of countries into two sets: poor countries and rich countries. Every day, geopolitical instability becomes more tangible and hard to be solved and it is clear that its origin is the growing economic inequality 'within' and 'between' countries.

In the contemporary global scenario, the question posed by Adam Smith (on the causes of the different levels of nations' wealth) resounds highly. Our belief is that a closer relationship between welfare economics and ethics could be an important starting point for the solution to the serious problems which come from the economic development of the world.

In this introduction we recall the essential features of the theory that underlies the so-called welfare economics ${ }^{2}$ in order to outline the ethical and unethical profiles of this theory, and especially to observe the consequences on the final allocation of resources. The description is aimed at analysing the possible links with ethics and consequently to provide useful suggestions for economic policy.

Welfare economics is the part of neoclassical microeconomics that analyses the characteristics of the final allocation of resources, in terms of collective benefits, in a context of general competitive equilibrium. The two basic theorems of welfare economics, called the First and Second Theorem of Welfare Economics, express the main thesis of the microeconomic analysis on the allocation of resources in an economic system based on a competitive market mechanism and on individual self-interested behaviours. These behaviours are aimed at utility maximization by individual consumers and at profit maximization by business enterprises. It should be noted that the hypotheses which are referred to by welfare economics are those that neoclassical theory assumes to be the basis of the competitive general equilibrium model:

(1) decentralized economy (market economy, decentralized decision-making, absolute freedom in the individual economic decisions, self-interested behaviours, utility functions of consumers and profit functions of firms independent of the choices of others, namely the absence of externalities in consumption and production);

\footnotetext{
${ }^{1}$ Economic policy is the denomination of the branch of scientific studies which refers to the interventions in an economic system taken by a government in order to influence the evolution of the economic variables toward predetermined objectives.

${ }^{2}$ Welfare economics (without another specification) is the branch of economics, established in the $20^{\text {th }}$ century, that focuses on the optimal allocation of resources resulting from a competitive process of price formation. This branch of microeconomics analyses the consequences on the distribution of resources and on the collective welfare deriving from the existence of perfect competition in all markets.
} 
(2) perfect competition in markets, with the condition of trading exclusively in the equilibrium of the markets themselves;

(3) the presence of private goods and services and the absence of public goods.

The aim of this section is to outline the ethical and unethical profiles of these assumptions and their consequences on the final allocation of resources under the approach based on so-called strong methodological individualism. This analysis is made without considering the circumstances in which the so-called failures of the competitive market occur; the failures can be mainly identified in the following alternative conditions: a limited number of market participants, trade which is out of equilibrium, asymmetric information, externalities in consumption and in production, and public goods. It should be noted that these alternative conditions, implying market failures, require a revision of the neoclassical formulation of the general competitive equilibrium model, regardless of ethical considerations. Therefore, focusing attention mainly on the ethical aspects of welfare economics, the neoclassical approach of general competitive equilibrium without market failures is considered the more appropriate for this analysis.

Under neoclassical assumptions without market failures, the theory shows that the competitive mechanism leads to a final allocation of resources characterized by some properties, which can be expressed by the so-called Pareto-optimality ${ }^{3}$ of an allocation. In the economic literature, the concept of Pareto-optimality is synonymous with allocative efficiency, which is optimality for the common welfare. To understand this concept, it is firstly necessary to clarify the meaning of allocation improvable for the common welfare. An allocation of resources can be improved, according to Pareto's definition, if it is possible to increase the utility and/or profit of at least one of the individuals in the system, without causing a decrease in the utility and/or profit of any other individual. The allocation of resources is optimal under the Pareto criterion if no further improvements can be made in terms of individual welfare for every subject. This is equivalent to saying that, starting from a Pareto-optimal allocation, any attempt to increase the utility and/or profit of even one of the individuals of the system will inevitably lead to the reduction of utility and/or profit of at least one individual.

The main theoretic results of welfare economics in its original formulation (by the neoclassical foundation) are based on the above-mentioned criterion, and are included in the well-known two theorems of welfare economics. ${ }^{4}$ The first theorem states and proves that every perfectly competitive general equilibrium generates a Pareto efficient

\footnotetext{
${ }^{3}$ This term comes from Vilfredo Pareto, who was the Italian economist and sociologist who succeeded Walras in the teaching of Economics at the University of Lausanne, in the early 1900s. He was famous for his contributions to the general equilibrium model of his predecessor, in particular for the indifference curves in the analytical approach to analyse consumer's preferences and for his contribution to the development of welfare economics.

${ }^{4}$ The principles of welfare economics are rigorously expressed in a lot of scientific contributions and books of economic theory. Cf. J.R. Hicks, The Foundations of Welfare Economics, "The Economic Journal” 1939, Vol. 49, pp. 696-712; J. Quirk, R. Saposnik, Introduction to General Equilibrium and Welfare Economics, McGraw-Hill, New York 1968; V. Walsh, H. Gram, Classical and Neoclassical Theories of General Equilibrium: Historical Origins and Mathematical Structure, Oxford University Press, Oxford 1980; A. Mas-Colell, M.D. Whinston, J.R. Green, Microeconomic theory, Oxford University Press, Oxford 1996; G. Impicciatore, Introduzione alla moderna microeconomia, ed. CEDAM, Padova 2006; W. Beckerman, The Role of Welfare Economics [in:] Economics as Applied Ethics, Palgrave Macmillan, Cham 2017.
} 
allocation of resources. The second theorem shows that, in a decentralized economy, any allocation of resources that is optimal according to the Pareto criterion is achieved by a mechanism of price formation of a perfectly competitive nature if this mechanism is left to act freely.

These results show a correspondence between perfectly competitive equilibria and optimal allocations, considering the Pareto criterion to be the foundation of welfare states. Some important observations on the role of government intervention in the economy must be added to these considerations. According to the contents of the first theorem of welfare economics, it is possible to say that, if economic agents (consumers or businesses) can pursue their personal objectives and there is perfect competition in the markets (in the absence of externalities and public goods), then the overall result of their actions, clearly selfish, is a profitable situation for the community. From similar arguments it may be deduced that there is no theoretical reason to justify government intervention, considering laissez faire the only rational attitude of the government; this behaviour still must be completed on the basis of possible contingent aspects. ${ }^{5}$

Summing up the various aspects outlined above in the light of the theory of welfare economics, the role of government should be identified by the following objectives:

(1) to guarantee freedom in choice and action to every economic agent;

(2) to ensure perfect competition in the markets;

(3) to ensure the fair distribution of resources (because the competitive mechanism cannot guarantee this result by itself);

(4) to establish mechanisms aimed at implementing the right behaviours if there are externalities that affect the social optimality of the allocations, or if there is any disadvantage for some individuals or groups because of imperfect information or circumstances that alter the social optimality;

(5) to ensure the efficient use and management of public resources (in the presence of public goods, in addition to private goods).

The conclusions deducible from the two theorems of welfare economics are undoubtedly significant; however, they do not solve completely the problem of the best distribution of resources among the members of any community. To understand this last statement, it should be noted that the Pareto-optimality criterion leads to the determination of an unlimited number of allocations (each dependent on the allocation of initially owned resources) which are all characterized by allocative efficiency, and it does not allow one to determine if, among these allocations, there are some more desirable than all others. This happens even when the resulting allocations of resources are characterized by significant differences in the levels of welfare enjoyed by the agents participating in the distribution processes of the market economy. In other words, in some Pareto-optimal allocations, there would be a concentration of one or more resources in favour of an individual who would be deprived of the same resources in other allocations which are still considered efficient. In this case, there is a problem concerning not only the efficiency of the allocation of resources, but also its 'equity'. It is possible to deduce that it is necessary to superimpose

$\overline{{ }^{5} \text { G. Impicciatore, op. cit., p. } 349 .}$ 
(on the Pareto criterion) another 'rule' for choosing the allocation (among the infinite Pareto-optimal allocations) which is more consistent with the principles of distributive justice, which had to be clearly defined previously. ${ }^{6}$

The above-mentioned considerations are related to the assumptions of economic theory which concern welfare economics in its original formulation. A development of this theoretical approach is based on the definition of analytical functions of public welfare to be maximized by a government (policymaker) under the constraints dictated by the real situation of the economic system and the existing institutions: this is the so-called New Welfare Economics.

It is certainly difficult to compare the principles of economic liberalism and those of social ethics because of the imperfect coincidence between freedom and ethics (freedom certainly is an achievement worthy of being labelled 'ethical', but ethics does not imply absolute freedom). The aim of the reflections included in this essay is to search for possible solutions to the problem of integrating welfare economics (the essence of which is based on individual freedom) with social ethics.

In relation to this theme, the studies of Amartya K. Sen, a philosopher and economist of great intellectual openness, are very interesting.?

Sen observes that in the evolution of economic thought - from Smith's contributions until nowadays - the improper use ${ }^{8}$ of the hypothesis regarding the self-interested behaviours of the economic agents of a market economy has damaged the quality of the economic analysis of resource distribution problems, producing a deep detachment between economics and ethics, leading to the idea that economic freedom is antithetical but has ethical aspects. ${ }^{9}$ In Sen's thought, this detachment is one of the major deficiencies of contemporary economic theory, and certainly has negative consequences for both areas of study.

Sen notes that a central aspect of ethics is to influence positively human behaviours; then, considerations coming from welfare economics, as potentially ethical, should be able to influence the real behaviour of every individual and, therefore, be important for contemporary economic theory, but this has not happened..$^{10}$ Sen says that it is necessary to enrich the theory of welfare economics by paying more attention to ethics.

The purpose of the next section is to suggest two possible solutions to the problem concerning the integration of welfare economics and ethics. The first solution is aimed at determining the optimal combination of liberal economic principles and social ethics ones, without modifying the theoretical construction of neoclassical welfare economics. The second solution, which is suggested by Sen, is aimed at integrating welfare economics with ethical considerations, by introducing some innovative concepts related to human freedom in place of basic neoclassical concepts.

\footnotetext{
${ }^{6}$ G. Impicciatore, op. cit., p. 328.

${ }^{7}$ In particular, in this paper there are references to Sen's contributions presented at conferences held in Berkeley in 1986 at the University of California. A.K. Sen, On Ethics and Economics, Blackwell, London 1988.

${ }^{8}$ Too many economists based their analysis on Smith's thesis which claims that individuals contribute to common welfare just because they are selfish people.

${ }^{9}$ A.K. Sen, On Ethics..., pp. 27-28.

${ }^{10}$ Ibidem, pp. 51-52.
} 


\section{Two possible solutions aimed to the integration of welfare economics and ethics}

The first solution is based on the idea of saving the consistency with welfare economics. It can be interpreted as a compromise which leads to the determination of an optimal combination between the Pareto criterion and the distributive justice principle. It is useful to start from an observation made by Sen, and to contrast it with a different observation. Sen says that even if an economy or a society is in a situation in accord with the optimality criterion formulated by Pareto, such situations may be absolutely disgusting. ${ }^{11}$

It is very important to highlight that this type of interpretation, also expressed by other economists in a less sententious way, is based on the idea that the Pareto-optimality of an allocation is linked to a sort of non-modifiability, confusing this presumed 'non-modifiability' with a kind of 'uniqueness'. But the Pareto criterion does not have the meaning of unconditional prohibition to carry out a redistribution, it refers to the inefficiency of a 'local' nature, that is, to a circumstance seen as an isolated fact, and not compared with the full range of possible Pareto-optimal allocations. The Pareto criterion does not prohibit a choice between these infinite possibilities: between them there will certainly be one that can be defined as 'the excellent among the best ones' and that certainly will be 'less disgusting' than others.

These observations are clearly aimed at saving the concepts, criteria and results of welfare economics from the point of view of those theorists who, while remaining in the sphere of the economic liberalism approach, assign a central role to the government, allowing the superimposition of another criterion onto the Pareto criterion in order to choose a Pareto-optimal allocation among the infinite ones. This solution can be adopted after analysing the complex concept of redistribution of wealth and after defining the concept of 'distributive justice' in the sense of 'distributive fairness'. In fact, the criterion to be added is a rule of distributive fairness and it is possible to overlap it on the basic Pareto criterion, just because there are infinite Pareto-optimal states (allocations). This integration of the Pareto criterion with the rule of distributive justice could be seen as the result of an optimal combination between principles of a liberal nature and social ethics ones which comply with the requirements of all components of the economic system.

Government intervention would be better if applied to initial allocations than to final ones, because of the dependence of final optimal allocations on the initial distribution.

In this context, it becomes necessary to solve the problem of defining the concept of 'distributive equity', that is 'distributive fairness'.

The concept of 'fairness' can be applied to multiple contexts of distribution of resources, especially in a theoretical approach in which distributive equity would be a relevant target. For example, it is possible to refer to 'fairness' when income, wealth, or any type of resources are distributed in an egalitarian way (egalitarianism). The same concept may be referred to as the distribution of resources in proportion to the economic value of the contribution that each individual provides to the community (neoclassical analysis of the income distribution), but it is also possible to refer it to the context in which

${ }^{11}$ A.K. Sen, Collective Choice and Social Welfare, Holden Day, San Francisco 1970, p. 22. 
it is possible to ensure a minimum amount of wealth to all individuals, with the addition of another share in proportion to their social contribution (theoretical position that results from a combination of the previous two described). In addition, 'fairness' may be the main characteristic of the distribution of wealth determined by the competitive mechanism (economic liberalism). Certainly, other criteria of distribution of wealth may be considered 'fair' according to a predetermined definition of 'fairness'.

The choice of an equity criterion for the distribution of collective resources is almost always related to different political, religious, and philosophical ideologies: in fact, the doctrines which this analysis can refer to are political philosophy and moral philosophy.

The second solution, designed to enrich welfare economics with ethical considerations, comes from Sen's ideas and is aimed at founding 'economic well-being' in a revisited concept of 'freedom'. ${ }^{2}$ It is useful to note that Sen distinguishes two approaches that in the history of economic thought have characterized the evolution of economic science and that he calls 'ethical' and 'engineering' approaches. The first approach, according to Sen, originates from human motivations linked to questions about how it is possible to promote human good, or how individuals would live. The second is generated by the interest in solving logistical problems, whereby the objectives are outlined in a simple and direct way, and the commitment is to find an appropriate means to achieve them, so inducing a non-ethical conception of the economic science. ${ }^{13}$

Sen, on the other hand, highlights serious deficiencies in the interpretation given to the many different and complex aspects of the thought of Adam Smith. ${ }^{14}$ To better understand these observations on the thought of Smith, it is useful to refer to the essential result of the 'invisible hand theorem'. This was based by Smith on the idea that individuals serve the public interest precisely because they are selfish. This would be true without the assumption of the benevolence of economic actors, provided that there are the conditions of free choice in a competitive system. According to Sen, the assertors and defenders of self-interest motivated behaviour sought in Smith's thesis support that is hard to find on the basis of a more comprehensive and less distorted understanding of this author. It is just this narrowing of perspective over the Smithian view of human beings which can be seen, according to Sen, as one of the major deficiencies of contemporary economic theory. This is a serious impoverishment of the analysis that leads to a double consequence: the first one, more general, is the estrangement of economics from ethics, and the other, which has a more specific nature, is the weakening of the scope of welfare economics. Sen considers some parts of Smith's writings that refer to the economy and society, as well as to poverty and ethics in human behaviour, to be insufficiently discussed. These comments on the partial interpretation of Smith's thought are important because, as Sen points out, they help to understand two negative aspects that have characterized the development

\footnotetext{
${ }^{12}$ For a discussion of the motivations that bring the focus on well-being, see: J.A. McGregor, N. Pouw, Towards an Economics of Well-being, "Cambridge Journal of Economics” 2016, Vol. 41, pp. 1123-1142.

${ }^{13}$ A.K. Sen, On Ethics..., pp. 2-7.

${ }^{14}$ A. Smith, An Inquiry into the Nature and Causes of the Wealth of Nations, Edwin Cannan, New York 1776; idem, Essay on Philosophical Subjects, T. Cadell Jun. and W. Davies, London 1795; idem, Lectures on Jurisprudence [in:] Glasgow Edition of the Works and Correspondence of Adam Smith, Vol. V, eds. R.L. Meek, D.D. Raphael, P.G. Stein, Oxford Univesity Press, Oxford 1978[1763]; idem, The Theory of Moral Sentiments, A. Millar, London 1759.
} 
of modern economic thinking, namely the loss of relevance of welfare economics, and the detachment of economics from ethics. Moreover, Sen says that it may certainly be useful to exploit the original considerations written by Smith, not only those about the self-interested behaviour, often considered in the literature, but also those which refer to social aspects, as well as poverty and ethics in human behaviour. ${ }^{15}$

The feeling is that this type of study could support and integrate Sen's approach in order to determinate an appropriate solution of the problem.

Sen, while attributing a general importance to the results of welfare economics in its classical formulation (particularly to its ability to shed light on the mechanism of price formation, on the mutually beneficial nature of trade, on production, and on consumption motivated by personal interest), believes that the ethical content of this theory is rather limited. ${ }^{16}$

Among the main elements that determine these limits, Sen points out that the socially efficient allocation, according to the Pareto criterion, is determined by the competitive mechanism from a given distribution of endowments of goods and services. ${ }^{17}$ This implies that, as Sen says, the social optimum so determined shall be bound by the initial distribution of wealth, which is not revealed by individuals, given that the market mechanism does not provide the implementation of the correct detection of the initial allocation: it is possible to say that a Pareto-optimum of this type has a 'local' nature. Sen continues the analysis, observing that, if it was possible to disclose the information on the initial distributions of wealth (on which the final Pareto-optimal allocations depend), an initial allocation could be set in order to determine the most suitable final Pareto-optimal one: it would be possible, in other words, to determine a Pareto-optimum of a 'global' nature. However, Sen points out that, even if this information were somehow available, the problem of the political feasibility of a redistribution of initial wealth between individuals would arise, since it would also be necessary to make changes in 'property rights'. ${ }^{18}$

After analysing these and other limitations of the neoclassical theory on common welfare, and after observing that according to welfarism the only things which have an intrinsic value for the ethical evaluation of a situation are individual utilities, Sen proposes a substantial modification of this approach. Sen moves away from the distinction between the concepts of 'utility' and 'agency', based on the belief that people's right to act does not necessarily and exclusively have to be considered in relation to the achievement of concrete results and material welfare. ${ }^{19}$

Sen uses the term well-being and not welfare to indicate the status of a community that is free in a 'substantial' way and not just in a 'procedural' one. ${ }^{20}$ The well-being is intimately tied, according to Sen, not to the usefulness of the results, but to the following two aspects: the 'agency' and the 'substantial freedom'. The first one should be distinguished from well-being, and the second should be distinguished from procedural freedom. ${ }^{21}$

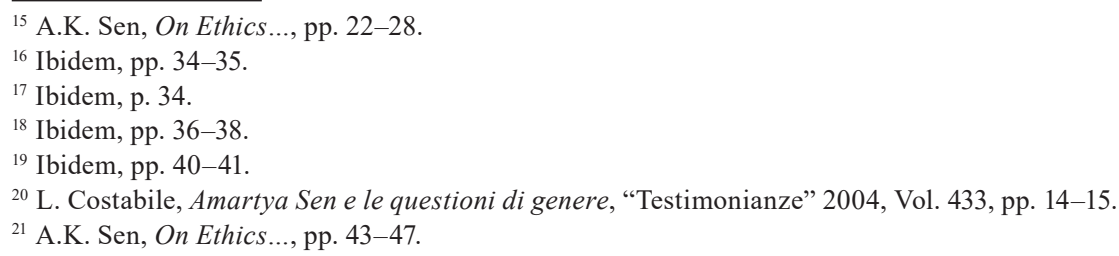


These last two aspects are closely tied together, although they could be analysed separately. Sen argues that it would be better to represent individual advantage by the freedom of the person and not by what the person can achieve on the basis of this freedom. These considerations lead to the necessity to evaluate individual rights, individual real opportunities, and individual substantial freedoms. ${ }^{22}$

In this broader view, welfarism, whether it is based on the criterion of Pareto-optimality or based on more complex criteria, such as utilitarianism, is considered a possible approach to the analysis of welfare economics, but not the only approach. The most evident departure from welfarism, according to Sen, is when importance is assigned to the 'agency': a person may be motivated to pursue objectives other than personal wellness or individual interests, and this happens not only for altruistic purposes or for 'benevolence'. When game theory is applied to economics, it proves that cooperation is an inevitable result, even in contexts that move from selfish behaviours characterized by complete contrast. ${ }^{23}$ The 'prisoner's dilemma' is an example of a non-cooperative game between two individuals motivated by one objective, which is to minimize their personal punishment. Through the repetition of the game and through the direct experience of the results of personal behaviour, it is possible to reach the choice to cooperate in order to achieve a certain reduction of the sentence. If this happens, it must be said that the cooperative outcome is not the result of altruism or benevolence, but it is the result of a system of rewards and punishments, directed and planned by an impartial operator who implements cooperative behaviour by applying opportune rules.

In relation to the issue of distributive justice, Sen adopts a consequentialistic vision on governments and social systems: they should be judged even by the consequences they produce on the living conditions of people. He believes that the responsibility of governments promotes the 'common good'. In Sen's thought, the 'common good' can be defined simply as the elimination of situations of 'deprivation'. ${ }^{24}$

The starting point of his project of promoting the 'common good' is the adoption of a 'fundamental concept of individual freedom'. ${ }^{25}$ 'Freedom', according to Sen, should not to identified with the mere 'non-violation' of a law (the concept of 'procedural freedom'). Its value lies in its enabling capabilities; it consists of all the opportunities it offers and in what it enables people to do. The 'basic capabilities' or 'substantial freedoms' (intended as the set of choices that an individual can do, i.e. the actual ability of an individual to do things considered to be good for himself) indicated by Sen are: the ability to survive, to be well nourished, to be free from disease, to receive medical care, and to access education. 'Deprivation' (in an absolute sense) for Sen is a lack of these basic capabilities. According to another example from Sen, it can be said that a rich man is freer than a poor man, because the rich man can choose to eat or to fast, while the poor man must necessarily fast: the range of choices of a rich person is wider than that of a poor person. Sen also deals with deprivation in a relative sense, referring to the circumstances in which, even if there are opportunities of choice for all individuals, these are not distributed in an egalitarian way. ${ }^{26}$

\footnotetext{
${ }^{22}$ Ibidem, pp. 47-51.

${ }^{23}$ N. Mattoscio, C. Pagliari, Equilibri economici non cooperativi e teoria dei giochi, ed. CEDAM, Padova 1990.

${ }^{24}$ L. Costabile, op. cit., p. 14.

${ }^{25}$ A.K. Sen, Development as Freedom, Oxford University Press, Oxford 1999.

${ }^{26}$ L. Costabile, op. cit., pp. 14-15.
} 
Sen's proposal is to evaluate the success of a social system through the dimension of the range of choices that it really allows to its members. His point of view is in the tradition of liberal thought, although it is not fully coherent with the 'libertarian' position of the Pareto criterion. In fact, the realization of substantial freedoms provides a redistribution of wealth from wealthy individuals to those less fortunate, in contrast to the inviolability of property titles held by libertarians. Social justice, as conceived by Sen, requires a reversal of classical utilitarianism, since it admits that a redistribution down of the rich and pro-poor should be done if it is necessary to treat a state of 'deprivation', even if such redistribution implies a reduction of the well-being of the well-to-do people. Sen's thought can be considered 'egalitarian', not in reference to the distribution of income in equal terms, but in reference to the equal distribution of opportunities of choice. His point of view might be called 'egalitarianism of substantial freedoms' ${ }^{27}$ His thought, in this sense, can be summarized by the title of his work of 1999, Development as Freedom.

\section{Some links between the two proposed solutions and criticism about their application}

The aim of this section is to describe the main critical aspects of the issues analysed in this paper, both in relation to some possible links between the two proposals described in the previous section and to the limits of their application.

The two approaches proposed in the previous section are quite different from each other because of their starting points. The first one is founded on the neoclassical theory of income distribution, which is a result of the analysis of the general competitive equilibrium, based on rational individual choices aimed at maximizing individual objectives (utility and profit). The second approach substitutes the importance of concrete results (utility and profit) with the importance of the faculty of choosing freely, so that the initial allocation of resources in a competitive economic system is not considered a combination of exogenous endowments, but becomes the primary objective to be ex ante determined according to the freedom principle based on the concept of 'agency'. Furthermore, the initial allocation is not defined by quantitative elements, but by a set of functionings which each individual must have the opportunity to carry out and among which each individual can freely choose his lifestyle.

On the other hand, the two proposed solutions are linked by three very important aspects which, probably, would characterize every issue which is related to the integration of economics and ethics. These aspects can be summarized in the following way:

(1) the unavoidability of government intervention aimed at improving the initial allocations of goods and services;

(2) the necessity of a political point of view which is ahead of the different ideologies (i.e. the necessity of a renunciation of political ideologies);

(3) the difficulty of applying the theory.

${ }^{27}$ Ibidem, p. 16. 
Firstly, the two proposals are correlated by the irreplaceable role of government (or policymaker). In fact, for the first solution, it is indispensable that the government carry out a redistribution of income (and/or wealth), in addition to the fundamental guarantee of competition, in order to apply the chosen criterion of distributive fairness. In the second solution, the possibility for each individual to choose combinations of functionings, especially the primary ones, depends strictly on political decisions. In this case, the unavoidability of government intervention is evident because the 'agency' of any individual is conditioned by the existence of political decisions aimed at ensuring the so-called 'substantial freedoms'. These statements on the role of government strictly refer to the determination and actuation of policy interventions regarding institutional and legislative changes and the related incentives and punishments. However, a significant role can also be carried out by individuals who are not in a government, but are motivated by social objectives and by altruism.

Another aspect which links the two above-described approaches is the necessity of transcending the orthodoxy of any ideology, especially in political decisions. The first proposal, in fact, is equivalent to hope for a government, whose policy would mix interventions aimed both at guaranteeing free and competitive markets and ensuring free economic individual choices, that is, avoiding a situation where individuals are not able to participate in market activities (both consumers and firms) because of their insufficient resources (of material and/or immaterial form). In contemporary developed economic systems, it is predominantly democratic governments which apply a combination of interventions as described herein; however, there may be a different degree of attention paid to the component related to the competitiveness of markets (of primary importance for a liberalistic government) or to that related to individual initial endowments of resources (the main priority for any 'welfarian' government). The combination of these socioeconomic objectives, so far from each other, can be reviewed as a mix of two inescapable concepts which may be used as ethical criteria for socioeconomic choices, i.e. 'merit' and 'necessity of help'; each individual has a right to be satisfied in relation to both these components of his life. The second proposal fundamentally goes beyond any ideological orthodoxy, by its own nature. In fact, it is based on a total revision of two important and antithetical concepts such as 'economic freedom' and 'economic equality'. The result is a mix of these concepts, which leads to an innovative model of government aimed at realizing policies able to reach 'the equality of substantial freedoms'. As an absolute conclusion, Sen proves an important thesis: this type of result cannot be obtained without democracy but can be obtained abandoning policies such as liberalistic and/or welfarian ones.

The third aspect which links the two solutions proposed in this paper is the difficulty of realizing the proposal themselves. There are interesting contributions aimed at applying these theoretical suggestions. In the following part of this section, there are some references to these studies. In relation to the first solution, and in particular to the problem of defining the concept of 'distributive equity', there are many studies, even as far back as the 1970s. Among these, it is useful to note the study about the concepts of 'equity' and 'equality' written by Bronfenbrenner. ${ }^{28}$ Furthermore, Crawford's paper describes a sim-

${ }^{28}$ M. Bronfenbrenner, Equality and Equity, "Annals of the American Academy of Political and Social Science" 1973, Vol. 409, pp. 9-23. 
ple operational procedure that, under reasonable economic assumptions, always generates Pareto-efficient egalitarian-equivalent allocations when agents know each other's preferences. ${ }^{29}$ Regarding the concept of the 'equity' of an allocation, the contribution of Duclos focuses on the definitions of 'vertical equity' and 'horizontal equity', and he argues that the 'horizontal equity principle' is not as straightforward as it is usually thought and that it requires advanced notions of justice and well-being. ${ }^{30}$ The recent contribution written by Sitarz investigates the relations between dynamic programming and the search of the Pareto-optimal allocations..$^{31}$ It is necessary to overlap the criterion of equity and/or distributive justice with the search of Pareto-optimal allocations. However, the possibility of applying this type of criterion, although studied and well determined, is crucially dependent on the political maturity of the government, which would be less myopic. In relation to the applicative problems of the second solution, there are studies on the determination of capabilities and functionings, on their measurement, on the possibility of estimating the same deprivations in particular areas, and on modelling deprivation in order to choose the best policy to adopt. However, these contributions have not yet produced a systematic methodology to be applied in contexts in which the quantitative analysis is of primary importance. Among these studies, the following citations may be useful. Grasso explored the possibility of using system dynamics to operationalize Sen's framework and investigated the architecture of the three-functionings model which he devised to represent human well-being. ${ }^{32}$ Robeyns discussed a set of methods for the selection of capabilities for quality of life measurement. ${ }^{33}$ De Stefanis and Sena adopt Sen's capability approach in order to compute a capability index, ranking individuals on the basis of their ability to transform health and economic resources into health functionings, and they show that, even when controlling for access to health resources, socioeconomic variables significantly affect the health functionings in the UK, thus suggesting the need for more egalitarian access policies to health care facilities. ${ }^{34}$ Krishnakumar and Ballon propose a suitable theoretical framework for operationalizing the capability approach and specify a structural equation model in order to account for the unobservable and multidimensional aspects characterizing the concept of human development, and to capture the mutual influence among different capabilities. ${ }^{35}$

\footnotetext{
${ }^{29}$ V.P. Crawford, A Procedure for Generating Pareto-Efficient Egalitarian-Equivalent Allocations, "Econometrica" 1979, Vol. 47, pp. 49-60.

${ }^{30}$ J.Y. Duclos, Innis Lecture: Equity and Equality, "The Canadian Journal of Economics/Revue Canadienne d'Economique" 2006, Vol. 39, pp. 1073-1104.

${ }^{31}$ S. Sitarz, Pareto Optimal Allocations and Dynamic Programming, "Annals of Operations Research" 2009, Vol. 172, pp. 203-219.

${ }^{32}$ M. Grasso, A Dynamic Operationalization of Sen's Capability Approach, Working Paper Series, No. 59, 2002, Dip. of Political Economics, University of Milan - Bicocca (Italy)

${ }^{33}$ I. Robeyns, Selecting Capabilities for Quality of Life Measurement, "Social Indicators Research" 2005, Vol. 74, pp. 191-215.

${ }^{34}$ S. De Stefanis, V. Sena, Health, Capabilities and Functionings: An Empirical Analysis for the UK, Working Paper, No. 151, 2006, Centre for Studies in Economics and Finance - University of Salerno (Italy).

35 J. Krishnakumar, P. Ballon, Estimating Basic Capabilities: A Structural Equation Model Applied to Bolivia, "World Development" 2008, Vol. 36, pp. 992-1010.
} 


\section{Conclusions}

Among the considerations contained in this paper, the main result to be emphasized is the necessity of government intervention both in the first and in the second solution. In order to achieve collective welfare, the government must intervene in modifying final 'allocations' or initial 'endowments'. In every case, the task is very complex because of the unavoidable contrast between government choices and individual ones, which comes from the contrast between collective and individual objectives. Freedom in markets and freedom in individual behaviour are mutually compatible and collectively beneficial if and only if the system is 'perfect'. The imperfections of the real economic systems can be neutralized by a 'good' government. Interventions on final allocations can mostly be realized by applying fiscal policy, while interventions on initial endowments should refer to many aspects, such as those related to Sen's 'substantial freedoms' (food, instruction, health care), or those related to (physical) capital endowments (fertile soil, houses). These last types of intervention can be beneficial for collective welfare; their positive effects can be obtained also in political contexts in which there is social deprivation and there is no democracy.

In addition to the above-analysed links, there is a most important correlation between the two solutions described in the second section: both the approaches require the integration of different doctrines and the work of researchers and scholars of different areas. This requirement is typical of every science which is reaching maturity.

The migration of people from their own countries toward unknown destinations, wars whose motivations hid an interest in energy sources, the conditions of poverty and hunger of too many individuals in the world - these are the voices that cry for help in the minds (and perhaps in the consciences) of contemporary researchers who study the economic distribution of wealth, inequality, and economic development.

It would be desirable to share the assertion of the economist Robert E. Lucas Jr. who says that the consequences for human welfare connected with this type of matter are simply disconcerting: after one reflects on them, it is difficult to think of something else. ${ }^{36}$

\section{References}

Beckerman W., The Role of Welfare Economics [in:] Economics as Applied Ethics, Palgrave Macmillan, Cham 2017.

Bronfenbrenner M., Equality and Equity, "Annals of the American Academy of Political and Social Science" 1973, Vol. 409, pp. 9-23.

Costabile L., Amartya Sen e le questioni di genere, "Testimonianze" 2004, Vol. 433, pp. 11-23.

Crawford V.P., A Procedure for Generating Pareto-Efficient Egalitarian-Equivalent Allocations, "Econometrica" 1979, Vol. 47, pp. 49-60.

${ }^{36}$ R.E. Lucas Jr., On the Mechanics of Economic Development, "Journal of Monetary Economics" 1988, Vol. 22, pp. 3-42. 
De Stefanis S., V. Sena, Health, Capabilities and Functionings: An Empirical Analysis for the UK, Working Paper, No. 151, 2006, Centre for Studies in Economics and Finance - University of Salerno (Italy).

Duclos J.Y., Innis Lecture: Equity and Equality, "The Canadian Journal of Economics/Revue Canadienne d'Economique" 2006, Vol. 39, pp. 1073-1104.

Grasso M., A Dynamic Operationalization of Sen's Capability Approach, Working Paper Series, No. 59, 2002, Dip. of Political Economics, University of Milan - Bicocca (Italy).

Hicks J.R., The Foundations of Welfare Economics, “The Economic Journal” 1939, Vol. 49, pp. 696-712.

Impicciatore G., Introduzione alla moderna microeconomia, ed. CEDAM, Padova 2006.

Krishnakumar J., P. Ballon, Estimating Basic Capabilities: A Structural Equation Model Applied to Bolivia, "World Development" 2008, Vol. 36, pp. 992-1010.

Lucas Jr. R.E., On the Mechanics of Economic Development, "Journal of Monetary Economics" 1988, Vol. 22, pp. 3-42.

Mas-Colell A., M.D. Whinston, J.R. Green, Microeconomic theory, Oxford University Press, Oxford 1996.

Mattoscio N., C. Pagliari, Equilibri economici non cooperativi e teoria dei giochi, ed. CEDAM, Padova 1990.

McGregor J.A., N. Pouw, Towards an Economics of Well-being, "Cambridge Journal of Economics" 2016, Vol. 41, pp. 1123-1142.

Quirk J., R. Saposnik, Introduction to General Equilibrium and Welfare Economics, McGraw-Hill, New York 1968.

Robeyns I., Selecting Capabilities for Quality of Life Measurement, "Social Indicators Research" 2005, Vol. 74, pp. 191-215.

Sen A.K., Collective Choice and Social Welfare, Holden Day, San Francisco 1970.

Sen A.K., Development as Freedom, Oxford University Press, Oxford 1999.

Sen A.K., On Ethics and Economics, Blackwell, London 1988.

Sitarz S., Pareto Optimal Allocations and Dynamic Programming, "Annals of Operations Research" 2009, Vol. 172, pp. 203-219.

Smith A., An Inquiry into the Nature and Causes of the Wealth of Nations, Edwin Cannan, New York 1776.

Smith A., Essay on Philosophical Subjects, T. Cadell Jun. and W. Davies, London 1795.

Smith A., Lectures on Jurisprudence [in:] Glasgow Edition of the Works and Correspondence of Adam Smith, Vol. V, eds. R.L. Meek, D.D. Raphael, P.G. Stein, Oxford Univesity Press, Oxford 1978[1763].

Smith A., The Theory of Moral Sentiments, A. Millar, London 1759.

Walsh V., H. Gram, Classical and Neoclassical Theories of General Equilibrium: Historical Origins and Mathematical Structure, Oxford University Press, Oxford 1980. 